\title{
The process by which editors are selected
}

Updated 09/16/2020

Precision Nanomedicine (PRNANO) is a platinum open access, peer-reviewed international journal (E-ISSN: 2639-9431) published by Andover House Inc., a not-for-profit 501(c)3 Public Charity, registered in Massachusetts USA, http://andoverhouse.org, a scientists-owned and operated 21stcentury publisher.

PRNANO has been selected as the official journal of the European Foundation for Clinical Nanomedicine. The journal is endorsed by the International Society for Nanomedicine (Basel, ISNM) and the European Society for Nanomedicine (Barcelona) - ESNAM. The NanoMedNorth Consortium and the British Society for Nanomedicine have also formed a partnership to support CLINAM society members.

The mission of the journal is to promote all practical, rational, and progressive aspects of nanomedicine, including theory and practice. As opposed to many other journals, we believe in publishing not only basic science but also translational, preclinical, clinical, as well as commercial topics that may move the field of medicine forward.

The journal's aim and scope are to distribute good quality, reproducible, and reliable articles with a quick turnaround time. This journal also aims to support publications of CLINAM members, members of other national nanomedicine societies, and nanomedicine researchers by providing a cutting-edge peer-review process. We offer a reliable source of information to societies, libraries, and the interested public without additional cost.

Preferred content includes basic, translational, and clinical research results addressing diagnosis, treatment, monitoring, prediction, and prevention of diseases enabled by nanotechnology, as well as translational research and commercialization of nanomedicines. We invite authors to submit original and reproducibility and replication studies, i.e., research manuscripts that reproduce, evaluate, and confirm research results. Similarly, discussions of negative results are also welcome as long as it moves the field forward.

The Journal's Editor-in-Chief (EiC) is nominated by the Advisory Board and selected by the Board of Directors of the Publisher, respecting the recommendations of the Journal Editorial Board.

The EiC leads the editorial team according to his or her vision to create a high-impact journal grounded in a strong understanding of the field and the needs of authors, readers, and reviewers and a vision for providing sustained value in the changing world of science and publishing. The EiC is responsible for defining the journal's aims, scope, and formats, building a strong network, recruiting exciting studies, and ensuring the quality and value of the journal as a forum for the best work across the entire field.

The Editor-in-Chief (EiC) is responsible for the content and merit of the journal and manages its organization and operations. The EiC obligations include structuring/restructuring the journal, formulating and revising editorial policies, building and operating infrastructure and networks, overseeing marketing, finding and qualifying customers, and recruiting and annually evaluating new editors and editorial board members in this vibrant field of research. The EiC must recruit members to the Board, so their expertise should cover the journal's professional areas and broadly reflect the nanomedicine community's scientific and geographic composition.

The EiC personally handles submissions from editorial board members.

Precision Nanomedicine has three bodies on its Editorial Boards: Associate Editors, the Honorary Board, and the Experts' Editorial Board. Their names, positions and contact information are published on https://precisionnanomedicine.com/editorial-board. Members of all three sub-groups are expected to actively support the journal to fulfill its mission, assist in formulating aims and policies, and help reach the journal's goals. The Editorial Board votes on key issues of the journal and 
suggests and confirms policy changes. Any Board member can nominate upcoming young scientists to the Journal's Rising Talent List.

Associate Editors (AEs) The body of Associate Editors should have 10,000 citations on average, and their expertise should broadly cover the professional areas published in the journal so that they can make quick and fair decisions. New members may be recommended by members of any of the three bodies of the Editorial Board based on their professional standing and invited and confirmed by the Editor-in-Chief in writing. Serving as an AE is strictly voluntary and assumes that the editor agrees with our mission statement and acts according to journal and publisher policies.

The role of an Associate Editor is to support daily journal operations actively. AEs make professional decisions about whether assigned manuscripts are worthy of publication. This activity includes inviting, reviewing, and evaluating manuscripts in their professional area for the journal; inviting reviewers, evaluating the quality of critiques and the submission's scientific merit, suggesting ways to make submissions better, and promoting the journal at professional meetings in their geographic and scientific areas including invitations of potential authors.

Most of PRNANO's Associate Editors and Editorial Board members have been working together for years (https://precisionnanomedicine.com/article/6467-the-story-of-precision-nanomedicine-thejournal. Associate Editors handle submissions that are not coming from board members. Assignments of manuscripts to Associate Editors are done by the EiC based on up-to-date CV, keywords, publications, and a paragraph describing their expertise in nanomedicine. AEs may submit manuscripts to their journal but are blinded from accessing their own submissions.

Associate Editors serve at the discretion of the EiC, as long as they choose to.

The role of an Honorary Editorial Board member (HB) is to ensure the journal's proper strategic direction. Honorary members are internationally renowned scientists and experts with 30,000 citations on average. New members may be recommended by members of any of the three bodies of the Editorial Board based on their professional standing and invited and confirmed by the Editor-inChief in writing.

Honorary Board members are not involved in daily operations. They have a unique view of the general direction of nanomedicine to give strategic advice to journal leadership when approached (at least once annually). They also promote the journal at professional meetings and invite manuscripts and potential authors. HB members are encouraged to submit manuscripts and perspectives in their primary area of interest to this journal anytime. They serve as long as they choose to.

The role of an Editorial Board member is to ensure the journal's scientific quality. Board members are expected to support their journal during their 2-year tenure actively, e.g., submit a manuscript, evaluate manuscripts strictly within their expertise, promote the journal at professional meetings in their geographic and scientific area, invite potential authors, and refer other outstanding scientists in their network as future Board Members.

The composition of the Editorial Board should reflect the geographic and professional areas in nanomedicine. We invite both proven world-renown scientists and promising young scientists in such a way that the Board - on average - maintains 9000 citations.

New board members are recommended by active Board members and then invited and confirmed by the Editor-in-Chief in writing. Scientists on the Rising Talents list are considered the future of nanomedicine and may move up to regular status after serving as reviewers and successfully publishing their first article in PRNANO.

Participation on the Board is strictly voluntary and assumes that all members agree with our mission statement and policies and actively support the journal. Editorial Board members serve two-year terms. Contributions from Editorial Board members are evaluated annually. Extension of membership is subject to renewal by the Editor-in-Chief based on demonstrated contribution. 